\title{
Simulation of Open Loop and Closed Loop Synchronous Buck Converter for LED Applications
}

\author{
Deekshitha $\mathbf{C}^{1}, \mathbf{K}$. Latha Shenoy ${ }^{2}$ \\ PG Scholar, Energy Systems Engineering., NMAM Institute of technology, Nitte, India ${ }^{1}$ \\ Assistant Professor, Dept of Electrical and Electronics Engineering, NMAM Institute of technology, Nitte, India ${ }^{2}$
}

\begin{abstract}
The demand of energy efficient lighting system is very essential in today's scenario. This is because the amount of energy consumption by lighting sources is approximately $20 \%$ of total electrical energy consumed in the world. In the recent years, LED lighting has emerged as a better energy efficient and eco-friendly solution for the residential and commercial lighting requirement. LED works on DC power and therefore it requires a device that can convert available AC power to DC power and regulate the current flowing through the LED during its operation. Thus to protect LED from line voltage fluctuations, a proper driver circuit is needed. In this paper the design of driver circuit for LED bulb with a synchronous buck converter is described. The simulation of driver circuit for both open loop and closed loop are done in MATLAB/SIMULINK software.
\end{abstract}

Keywords:LED, Synchronous buck converter, LED driver circuit, Open loop and Closed loop system.

\section{INTRODUCTION}

In the recent past, LED lighting has emerged as a better energy efficient and environment friendly solution for the general lighting purpose.TheLED technology so attractive because of its compact size, high reliability, chromatic variety, improved efficiency, good colour rendering index and low maintenance requirement [1].

In general LED requires an accurate DC power for its operation[2].This paper presents a design of driver circuit for LED bulb with a synchronous buck converter. Buck converter is a step-down DC-DC converter which effectively reduces the level of voltage as per the required application. But recent years for low voltage applications synchronous rectification and synchronous buck converters have been of great concern in power electronics due to increased efficiency. In synchronous buck converters the diode in the buck converter is replaced with another MOSFET. The introduction of MOSFET over a diode typically decreases the drop from $0.5 \mathrm{~V}$ to $1 \mathrm{~V}$ of diode to a value of $0.3 \mathrm{~V}$ or less [3]. This increases the efficiency of the converter by $5 \%$ or high. Thus efficiency of synchronous buck converter is higher than that for classical buck converter [10].

Synchronous buck converter uses two N-channel power MOSFETs, PWM control, synchronous MOSFET driver, power inductor and output capacitor. Incoming AC power is converted to DC power with the help of simple rectifier circuit. The rectified output is then given to the DC-DC converter through a DC link. To maintain constant DC voltage at the input of synchronous buck converter a DC link voltage is used. Incoming DC supply is reduced to lower level as required by the load through a synchronous buck converter.

This paper presents the application of synchronous buck converter to drive LED loads. The simulation of synchronous buck converter for both open and closed loop operation werealso discussed.

\section{SYNCHRONOUS BUCK CONVERTER}

The main goal of synchronous buck converter is to efficiently step down DC voltage to a lower level with minimum ripple. It mainly consist of two $\mathrm{N}$-channel power MOSFETs, PWM control, synchronous MOSFET driver, power inductor and output capacitor as shown in Fig.1(a).

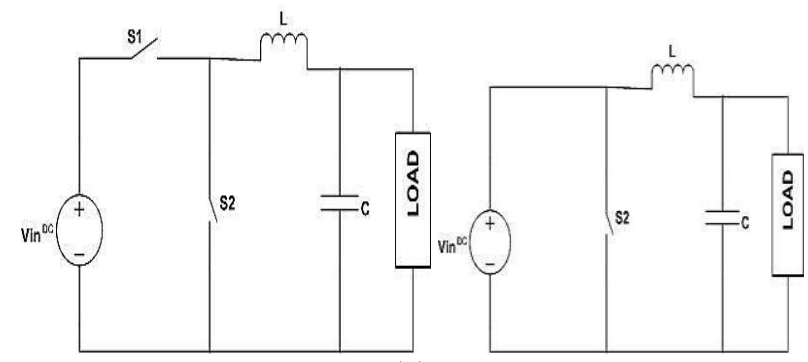

(a) 


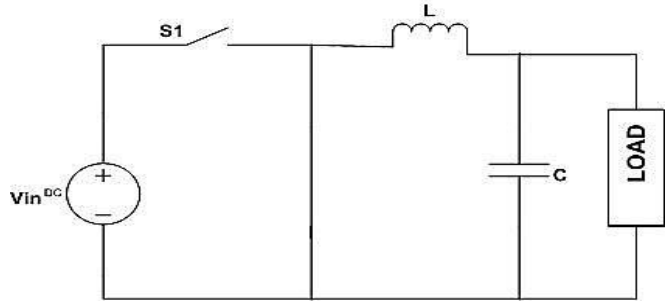

(b)

Figure 1(a) Buck dc-dc converter (b) Equivalent circuit for the switch closed (c) Equivalent circuit for the switch open

Synchronous MOSFET driver is used to control both power MOSFETs. When high side MOSFET $\left(\mathrm{S}_{1}\right)$ is $\mathrm{ON}$, low side MOSFET $\left(\mathrm{S}_{2}\right)$ is OFF; when low side MOSFET is ON, high side MOSFET is OFF. If both power MOSFETs are ON then high shoot through current can occur [3]. In order to avoid this effect delay times are usually used. The inductor is used to store energy when the high-side MOSFET is turned on; this energy is then used to supply current for the load when the high-side MOSFET is turned off. A low-side MOSFET across the load and inductor circuit provides a return path for the current during the off period of high -side MOSFET. A simple schematic is shown in Fig 2(a). The input to the filter is ' $V_{\mathrm{s}}$ ' when the switch $\mathrm{S}_{1}$ is $\mathrm{ON}$ and is zero when the switch $S_{1}$ is off, provided that the inductor current remains positive, keeping the switch $S_{2}$ is ON. If the switch is closed periodically at a duty ratio ' $\mathrm{D}$ ', the average voltage at the input of the filter is ' $\mathrm{V}_{\mathrm{s}} \mathrm{D}$ '. This analysis assumes that the low-side MOSFET remains ON for the entire time when the high-side MOSFET off, implying that the inductor current remains positive leading to continuous current mode.

When the high-side MOSFET switch is closed in the synchronous buck converter circuit of Fig 1(a), the low side MOSFET is open and fig 1(b) is an equivalent circuit. The voltage across the inductor is,

$$
\mathrm{V}_{\mathrm{L}}=\mathrm{V}_{\mathrm{S}}-\mathrm{V}_{0}=\mathrm{L} \frac{\mathrm{di}}{\mathrm{dt}}
$$

When the switch $S_{1}$ is open, the switch $S_{2}$ gets closed to carry inductor current and the equivalent circuit of fig 1 (c) applies. The voltage across the inductor when the highside MOSFET is open is,

$$
\mathrm{V}_{\mathrm{L}}=-\mathrm{V}_{0}=-\mathrm{L} \mathrm{di}_{\mathrm{L}} / \mathrm{dt}
$$

\section{III.LED DRIVER CIRCUIT}

LEDs are current driven source. Their brightness depends on current flowing through it. Let us consider a load of 9W LED.The LED selected is Edison C series 1W cool white LED. To get $9 \mathrm{~W}$ power nine such $1 \mathrm{~W}$ LEDs are arranged in series parallel connection such that three $1 \mathrm{~W}$ LEDs are connected in series and three such branches are connected in parallel.
Each LED having forward voltage of 3.4V. Thus here the output voltage is $10.2 \mathrm{~V}$, since we used buck converter input voltage selected is $15 \mathrm{~V}$.

The characteristics of Edison LED obtained from datasheet are shown in Table I.

\section{TABLE I LED PARAMETERS FROM EDISON C SERIES DATASHEET}

\begin{tabular}{|c|c|}
\hline Parameter & Value \\
\hline DC Forward Current & $350 \mathrm{~mA}$ \\
\hline Reverse Voltage & $5 \mathrm{~V}$ \\
\hline Forward voltage & $3.4 \mathrm{~V}$ \\
\hline Drive Voltage & $5 \mathrm{~V}$ \\
\hline Viewing Angle & $130^{\circ}$ \\
\hline Thermal resistance & $10^{\circ} \mathrm{C} / \mathrm{W}$ \\
\hline Max. Luminous Flux @ 350mA & $1301 \mathrm{~m}$ \\
\hline Colour & Cool white \\
\hline LED Junction Temperature & $125^{\circ} \mathrm{C}$ \\
\hline CRI & 68 \\
\hline
\end{tabular}

Input voltage, $V_{i n}=15 \mathrm{~V}$

Output voltage across the string of LEDs $=3 * 3.2=10.2 \mathrm{~V}$

Output current across the string of LEDs $=3 * 350 \mathrm{~mA}$ $=1050 \mathrm{~mA}$

Output voltage ripple, $\frac{\Delta V_{0}}{V_{0}}=10 \%$

Switching frequency, $f_{s}=25 \mathrm{kHz}$

Since the load is LED, the switching frequency should be greater than $100 \mathrm{~Hz}$ so the human eye does not perceive flicker. Hence the value of switching frequency is fixed at $25 \mathrm{kHz}$.

Period, $T=\frac{1}{f_{S}}=40 \mu S$

Duty cycle, $D=0.68$

Inductor current at boundary condition, $I_{L B}=I_{O B}=\frac{P_{0}}{V_{0}}=$ $0.882 A$

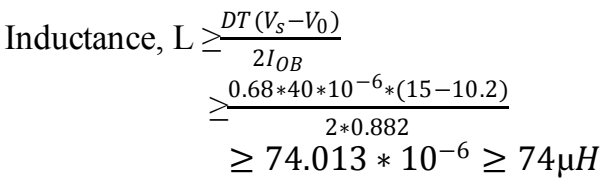

Capacitance, $C \leq \frac{T^{2}(1-D)}{8 L \frac{\Delta V_{0}}{V_{0}}} \leq \frac{\left(40 * 10^{-6}\right)^{2}(1-0.68)}{8 * 112 * 10^{-6} * 0.1}$ $\leq 8.647 * 10^{-6} \approx 9 \mu F$

\section{IV.SIMULATION RESULTS}

TABLE II SYSTEM PARAMETERS

\begin{tabular}{|c|c|}
\hline Parameter & Value \\
\hline Input Voltage $\left(\mathrm{V}_{\text {in }}\right)$ & $15 \mathrm{~V}$ \\
\hline Output Voltage $\left(\mathrm{V}_{0}\right)$ & $10.2 \mathrm{~V}$ \\
\hline Inductor $(\mathrm{L})$ & $74 \mu \mathrm{H}$ \\
\hline Capacitor $(\mathrm{C})$ & $9 \mu \mathrm{F}$ \\
\hline
\end{tabular}


Case-1: Open loop Synchronous Buck converter

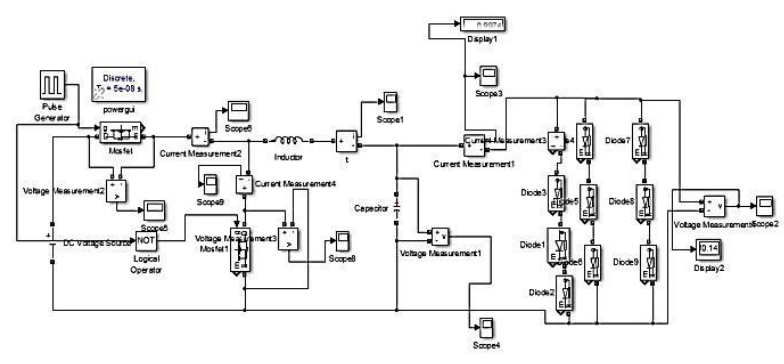

Fig.2Simulation model of Open loop Synchronous Buck converter

The simulation model of open loop synchronous buck converter is shown in Fig.2. Here the model is simulated with $15 \mathrm{~V}$ supply voltage andthe output waveform is observed. The simulation model wasmade asper the system parameters given in Table II. In this model the diode in ordinary buck converter is replaced with a MOSFET.

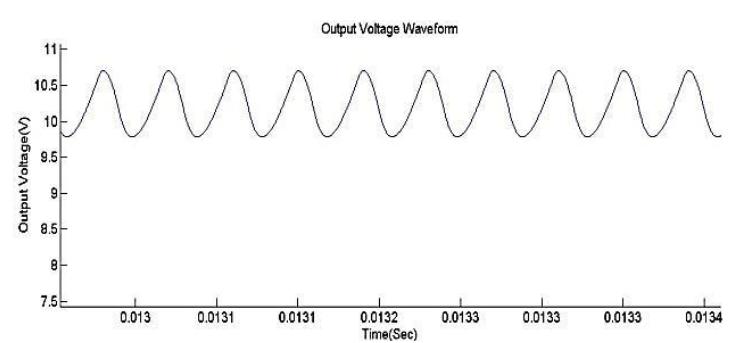

Fig.3 Simulation result of output voltage

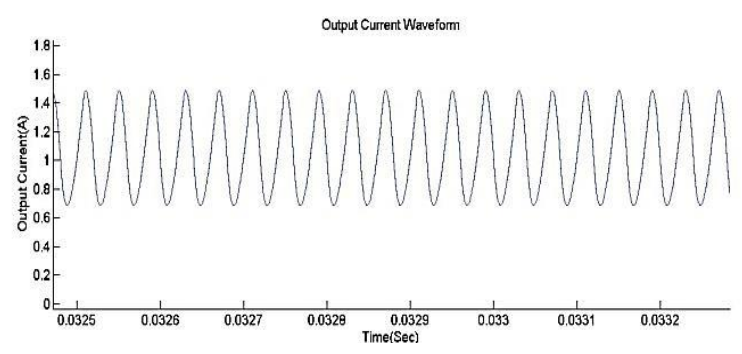

Fig.4Simulation result of output current

Fig. 3 shows the simulation result of the voltage across the LED string which is about $10.2 \mathrm{~V}$. Fig.4 shows the simulation result of output current. Average output current of about $1050 \mathrm{~mA}$ is observed.

The main disadvantages of open loop system are they are inaccurate and unreliable. They give inaccurate results because they cannot sense environmental changes and internal disturbances. To overcome these disadvantages, closed loop systems are used.
Case -2: Closed loop Synchronous Buck Converter

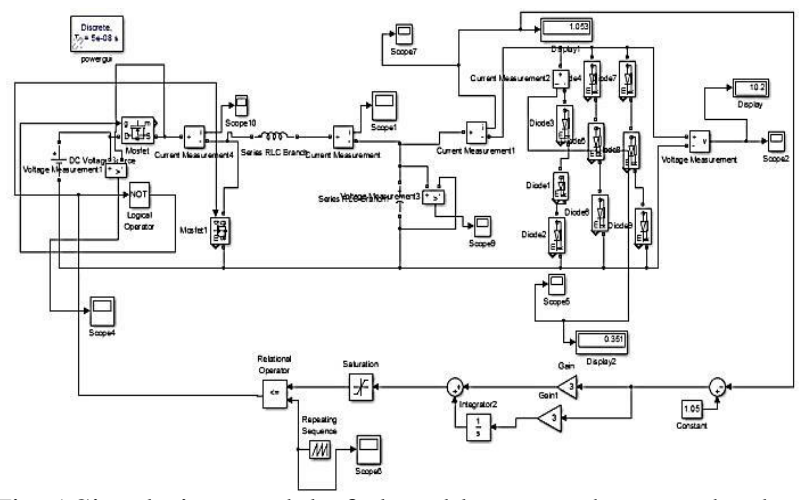

Fig.5 Simulation model of closed loop synchronous buck converter

Fig.5 shows the simulation model of closed loop synchronous buck converter. Here the model is simulated with $15 \mathrm{~V}$ supply voltage and the output waveform is observed. The simulation model was made as per the system parameters given in Table II.

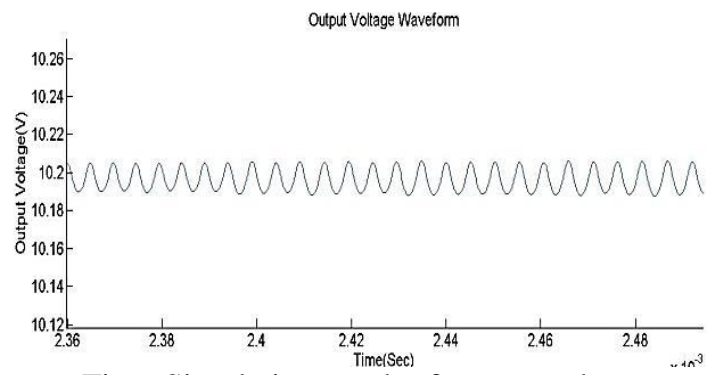

Fig.6 Simulation result of output voltage

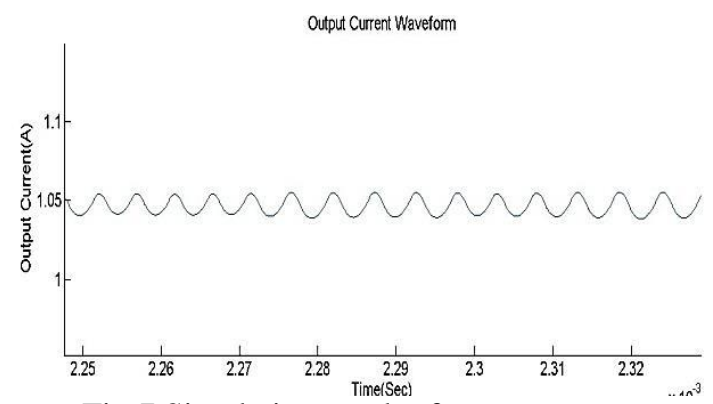

Fig.7 Simulation result of output current

Fig.6 shows the simulation result of the voltage across the LED string which is about $10.2 \mathrm{~V}$. Fig.7 shows the simulation result of output current. Average output current of about $1050 \mathrm{~mA}$ is observed. Closed loop operation gives us much accurate result compare to the open loop operation.In closed loop systems controller modifies and manipulates the actuating signal such that error in the system will be zero. These system senses environmental changes, as well as internal disturbances. So accuracy of such system is always very high. 


\section{CONCLUSION}

The design and analysis of synchronous buck converter for LED driver design is presented in this paper. The proposed converter can be used in low voltage high current applications. To increase efficiency synchronous buck converter is proposed. Modeling and simulation of proposed system is performed in MATLAB/SIMULINK environment.

\section{REFERENCES}

[1] Komine, T.Nakagawa.M'Fundamental analysis for visiblelightcommunication system using LED lights', IEEE Trans. Consum.Electron., 2004, 50, (1), pp. 100-107.

[2] S.Iturriaya Medina and P.RMartionez-Rodrigues,M.JuarezBalderas,J.M.Sosa and C.A . Limones "A buck converter controller design in an electronic drive for LED lighting applications", Lab of electricity and and power electronics,ITES1.

[3] J.Shreedhar and Dr.B.Basavaraju, "Design and Analysis of synchronous buck converter for LED application"International Conference on Advances in Electrical, Electronics, Information, Communication and Bio-Informatics (AEEICB16).

[4] Amrutha Thomas and Aju S Nair, " Driver design and Simulation for 6W LED bulb with PWM Dimming”, International Journal of Advance

[5] Research in Engineering Science and Technology ( IJAREST), Volume 2, Issue 12, December 2015.

[6] A. Kalirasu and S.S.Dash, " Modeling and Simulation of closed loop controlled buck converter for solar installation", International Journal of Computer and Electrical Engineering, Vol-3, No.2, April 2011.

[7] Kalpana S. Khandhediya, Prof.Suryaprakash Singh and Prof.B.M.Daxini, "Design and Simulation of open loop buck converter with losses", National Coference on Emerging trends in computer, Electrical and Electronics( ETCEE-2015).

[8] MOHAN, N., UNDELAND, T.M., and ROBBINS, W.P: "Power electronics: converters,applications and design" (Wiley, 1995, $2^{\text {nd }}$ Edn.).

[9] Synchronous Buck Converter Design Using TPS56XX controllers in SLVPx EVMs User's Guide, Texas Instruments, Sep 1998.

[10] Er.Vishal Mehta and Er. Pradeep Malik, "Comparison between Asynchronous and Synchronous buck converter topolgy", International Journal of Applied Engineering Research, ISSN 09734562 Vol.7 No.11 (2012)

[11] Torok, L., Beczkowski, S., Munk-Nielsen, S., Gadegaard, J., Kari, and T.,Pedersen, K.: 'High output LED-based profile lighting fixture'. Proc.37th Annual Conf. on IEEE Industrial Electronics Society IECON,2011, pp. 2941-2946. 